\title{
Editorial
}

\section{Polymeric Scaffolds for Tissue Engineering}

\author{
Xiaoming Li, ${ }^{1}$ Tsukasa Akasaka, ${ }^{2}$ and Nicholas Dunne ${ }^{3}$ \\ ${ }^{1}$ Key Laboratory for Biomechanics and Mechanobiology of Ministry of Education, School of Biological Science and Medical Engineering, \\ Beihang University, Beijing 100191, China \\ ${ }^{2}$ Department of Biomedical Materials and Engineering, Graduate School of Dental Medicine, Hokkaido University, \\ Sapporo 060-8586, Japan \\ ${ }^{3}$ School of Mechanical \& Aerospace Engineering, Queen's University of Belfast, Belfast BT9 5AH, UK \\ Correspondence should be addressed to Xiaoming Li; x.m.li@hotmail.com
}

Received 6 August 2014; Accepted 6 August 2014; Published 20 August 2014

Copyright (C) 2014 Xiaoming Li et al. This is an open access article distributed under the Creative Commons Attribution License, which permits unrestricted use, distribution, and reproduction in any medium, provided the original work is properly cited.

A fundamental problem that affects all fields of surgery is the paucity of autologous tissue available for surgical reconstructive procedures. When a surgeon removes a tissue that is diseased or damaged, or when a surgeon replaces a tissue that is congenitally absent, the best results are obtained when an individual's own tissues are used for the surgical repair. When it is not possible, the surgeon is forced to use alternative biomaterials and usually selects from either prosthetic, manmade synthetic materials or from biologic materials derived typically from allografts or xenografts [1]. Tissue engineering is a multidisciplinary science that attempts to create living biomaterials from a patient's own cells, which has been an area of immense research in recent years because of its vast potential in the repair or replacement of damaged tissues and organs [2-4]. Scaffold is one of the three most important factors in tissue engineering.

According to Hutmacher [5] a scaffold should have the following main characteristics: it should (1) be bioresorbable and biocompatible with a controllable degradation and resorption rate to match cell/tissue growth in vitro/vivo; (2) have a suitable surface chemistry for cell attachment, proliferation, and differentiation; (3) be three-dimensional and highly porous with an interconnected porous network for cell growth, flow transport of nutrients, and metabolic waste; and (4) have proper mechanical properties to match the tissues at the site of implantation [6].

Scaffolds lie at the heart of all the new tissue engineering approaches because they not only provide mechanical support for embedded cells but also regulate various cellular behaviors by recruiting specific biomolecules or growth factors. Polymeric scaffolds are one of the most widely used scaffold types because of their satisfactory formability, mechanical properties, biocompatibility, and controllable biodegradability [7-9]. To date, polymeric scaffolds have been largely applied to repair hard and soft tissues. However, there are still many challenges that need to be addressed, such as the development of satisfactory processing techniques so as to achieve homogeneous structure and composition throughout the scaffolds and to obtain well-defined internal structures with interconnected porosity to host most cell types. Moreover, additional studies are desired to figure out how to create desirable polymeric scaffolds that serve various functions, including immobilization of transplanted cells, formation of a protective space to prevent unwanted tissue growth into the wound bed while allowing healing with differentiated tissue, and directing migration or growth of cells via scaffold surface properties or via release of soluble bioactive molecules such as growth factors, hormones, and/or cytokines.

Currently, many novel issues on polymeric scaffolds for tissue engineering have been supported. Scaffolds fabricated by using materials such as nanoparticles, nanofibers, nanotubes, and other materials in nanoscale have been tried in tissue engineering. Besides, new technologies which can be available for tissue engineering have been studied.

According to the researches that have been done, kinds of fibers or tubes alternatives have been employed to reinforce the scaffolds for repairing specific tissues, such as ceramic 
fibers/tubes, and polymer fibers/tubes [10-13]. The nanomaterials reinforced composites can not only enhance the mechanical property but also improve the biocompatibility and bioactivity of scaffold. In this special issue, several articles are mainly focused on the some specific applications of scaffolds reinforced by nanofibers or nanoparticles. A few novel materials systems are demonstrated, such as nanohydroxyapatite/polyamide 66 composite and HA/collagen/PLA composites. Numerous research programs regarding the material systems which are available for scaffold used for tissue engineering, as well as the new technology, are developed. 3D printing technology has recently gained substantial interest for potential applications in tissue engineering due to the ability to make a three-dimensional object of virtually any shape from a digital model. 3D-printed biopolymers, which combine the $3 \mathrm{D}$ printing technology and biopolymers, have shown great potential in tissue engineering application and are receiving significant attention [14-16].

All in all, the issue will give a presentation about scaffolds fabricated using novel system or technology, and, most importantly, it will provide a general guide for the fabrication of more desirable scaffolds for tissue engineering.

Xiaoming $\mathrm{Li}$

Tsukasa Akasaka

Nicholas Dunne
[11] X. Li, Q. Feng, and F. Cui, "In vitro degradation of porous nanohydroxyapatite/collagen/PLLA scaffold reinforced by chitin fibres," Materials Science and Engineering C, vol. 26, no. 4, pp. 716-720, 2006.

[12] X. M. Li, Y. B. Fan, and F. Watari, "Current investigations into carbon nanotubes for biomedical application," Biomedical Materials, vol. 5, no. 2, Article ID 022001, 2010.

[13] X. M. Li, R. R. Cui, W. Liu et al., "The use of nano-scaled fibers or tubes to improve biocompatibility and bioactivity of biomedical materials," Journal of Nanomaterials, vol. 2013, Article ID 728130, 16 pages, 2013.

[14] T. Serra, M. A. Mateos-Timoneda, J. A. Planell, and M. Navarro, "3D printed PLA-based scaffolds: a versatile tool in regenerative medicine," Organogenesis, vol. 9, no. 4, pp. 239-244, 2013.

[15] S. Bose, S. Vahabzadeh, and A. Bandyopadhyay, "Bone tissue engineering using 3D printing," Materials Today, vol. 16, pp. 496-504, 2013.

[16] F. Pati, J.-H. Shim, J.-S. Lee et al., "3D printing of cell-laden constructs for heterogeneous tissue regeneration," Manufacturing Letters, vol. 1, pp. 49-53, 2013.

\section{References}

[1] A. Y. Lee, N. Mahiler, C. Best, Y. U. Lee, and C. K. Breuer, "Regenerative implants for cardiovascular tissue engineering," Translational Research, vol. 163, no. 4, pp. 321-341, 2014.

[2] X. M. Li, L. Wang, Y. B. Fan, Q. L. Feng, F. Z. Cui, and F. Watari, "Nanostructured scaffolds for bone tissue engineering," Journal of Biomedical Materials Research A, vol. 101, no. 8, pp. 24242435, 2013.

[3] S. P. Nukavarapu and D. L. Dorcemus, "Osteochondral tissue engineering: current strategies and challenges," Biotechnology Advances, vol. 31, no. 5, pp. 706-721, 2013.

[4] X. H. Liu, X. M. Li, Y. B. Fan et al., "Repairing goat tibia segmental bone defect using scaffold cultured with mesenchymal stem cells," Journal of Biomedical Materials Research B, vol. 94, no. 1, pp. 44-52, 2010.

[5] D. W. Hutmacher, "Scaffolds in tissue engineering bone and cartilage," Biomaterials, vol. 21, no. 24, pp. 2529-2543, 2000.

[6] X. Li, Y. Huang, L. Zheng et al., "Effect of substrate stiffness on the functions of rat bone marrow and adipose tissue derived mesenchymal stem cells in vitro," Journal of Biomedical Materials Research A, vol. 102, no. 4, pp. 1092-1101, 2014.

[7] D. O. Fauza, "Tissue engineering in congenital diaphragmatic hernia," Seminars in Pediatric Surgery, vol. 23, pp. 135-140, 2014.

[8] Y. Naito, K. Rocco, H. Kurobe, M. Maxfield, C. Breuer, and T. Shinoka, "Tissue engineering in the vasculature," The Anatomical Record, vol. 297, no. 1, pp. 83-97, 2014.

[9] T. J. Keane and S. F. Badylak, "Biomaterials for tissue engineering applications," Seminars in Pediatric Surgery, vol. 23, pp. 112118, 2014.

[10] X. M. Li, H. F. Liu, X. F. Niu et al., "The use of carbon nanotubes to induce osteogenic differentiation of human adipose-derived MSCs in vitro and ectopic bone formation in vivo," Biomaterials, vol. 33, no. 19, pp. 4818-4827, 2012. 

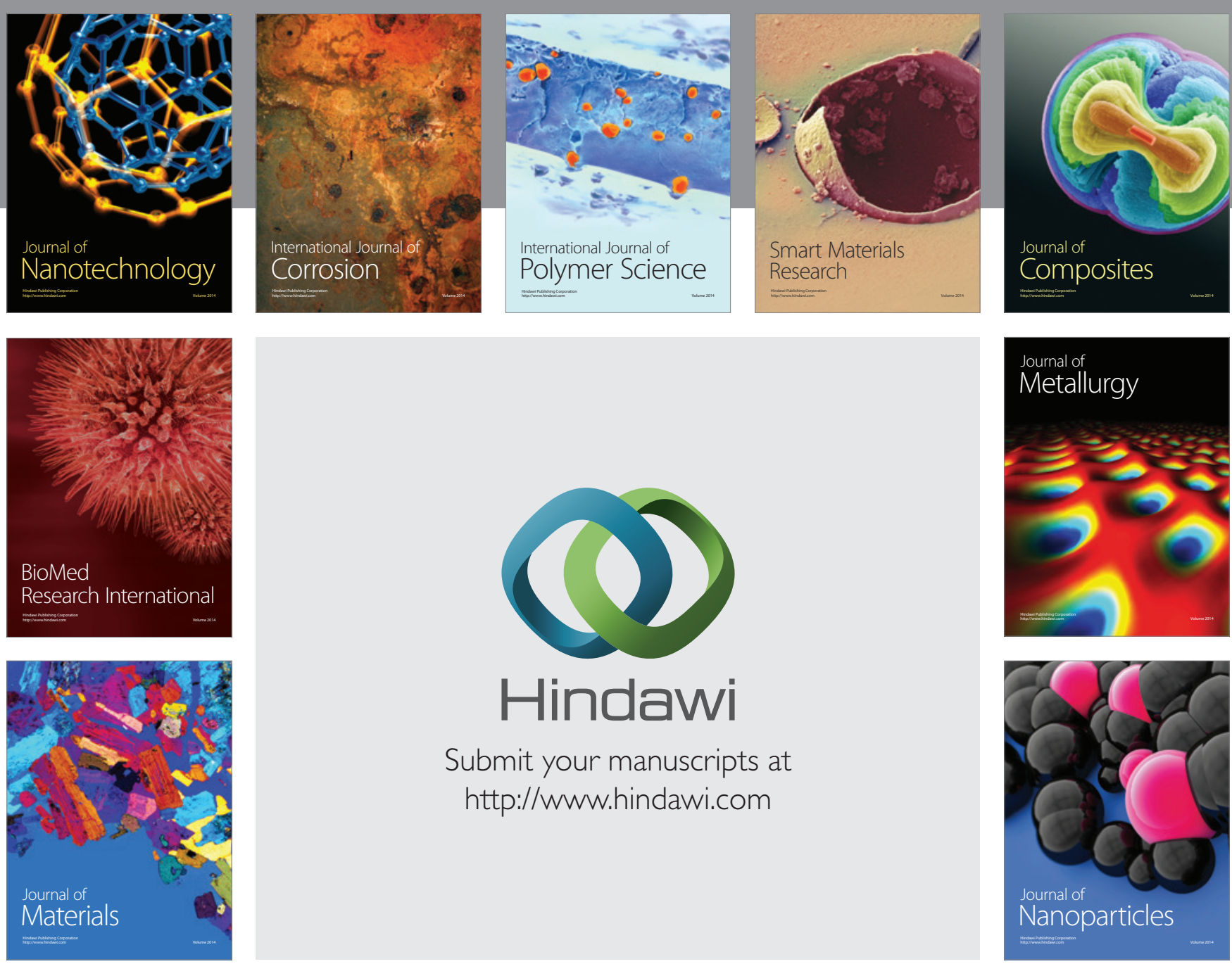

Submit your manuscripts at http://www.hindawi.com
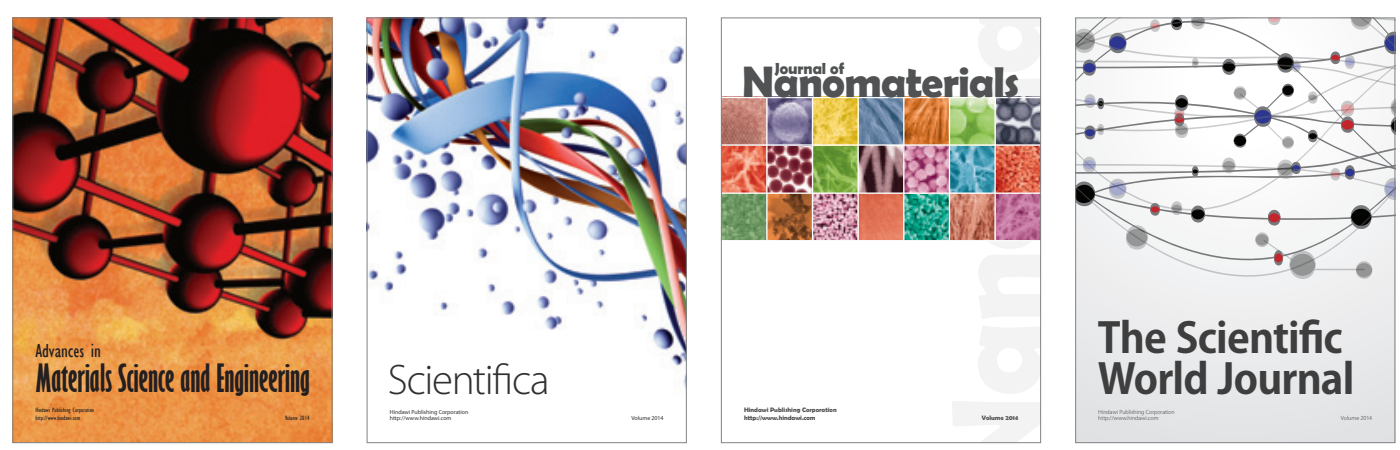

\section{The Scientific World Journal}
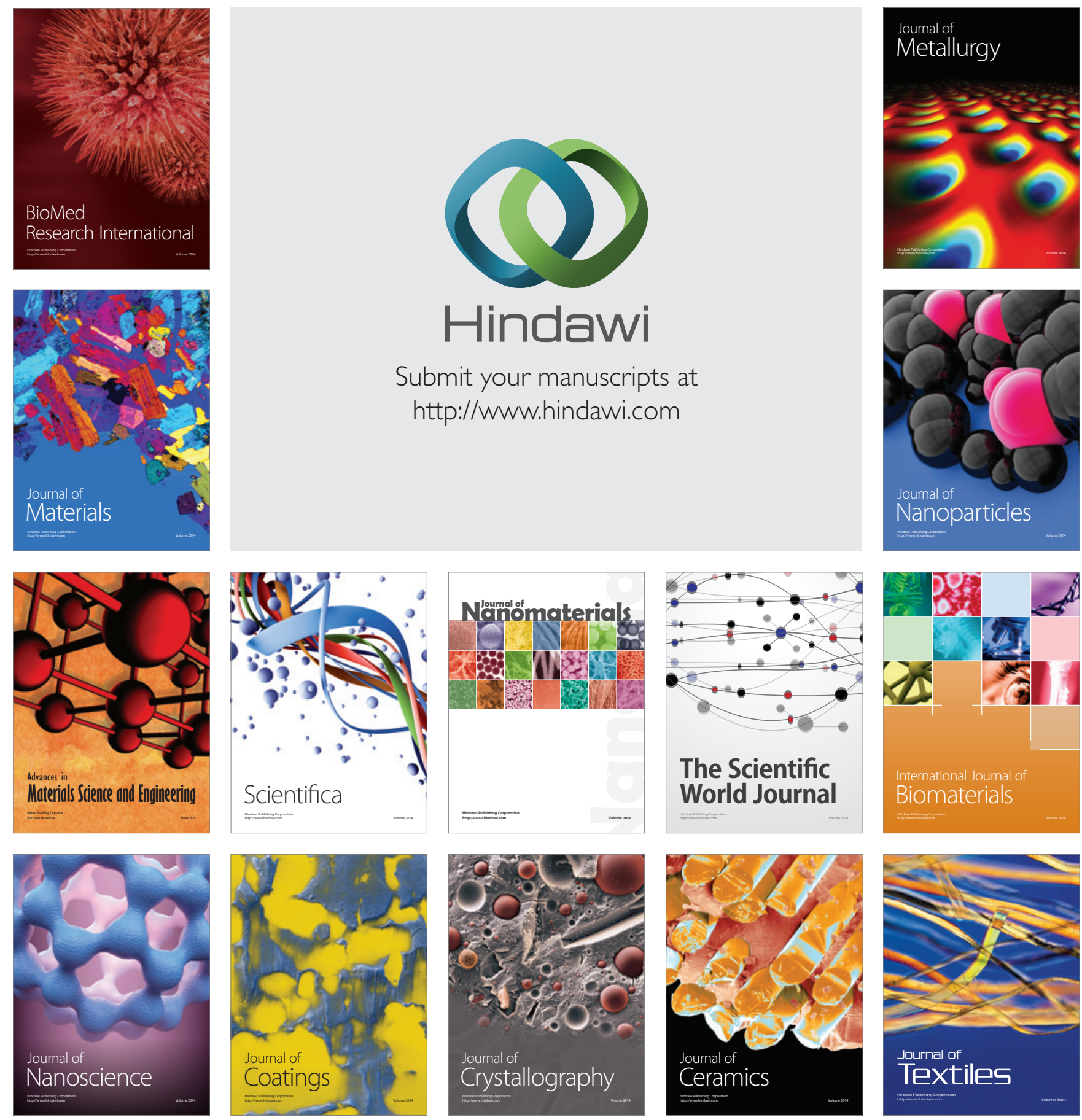